\title{
利用冠层光谱监测小麦籽粒蛋白质积累动态
}

\author{
冯 伟 ${ }^{1,2}$ 朱 艳 ${ }^{1} \quad$ 曹卫星 $^{1, *}$ 朱云集 $^{2}$ 郭天财 $^{2}$ \\ ${ }^{1}$ 南京农业大学 / 江苏省信息农业高技术研究重点实验室, 江苏南京 $210095 ;^{2}$ 河南农业大学 / 国家小麦工程技术研究中心, 河南郑 \\ 州 450002
}

摘 要: 于 2003-2006 年连续 3 个生长季, 利用不同小麦品种在不同施氮水平下进行大田试验, 在小麦不同生育期 采集田间冠层高光谱数据并测定植株氮素含量、生物量和籽粒蛋白质积累量(GPA)。通过定量分析小麦籽粒蛋白质积 累量、冠层氮素营养指标及高光谱参数的相互关系, 确立了能够准确预测小麦籽粒蛋白质积累动态的敏感光谱参数 及定量模型。结果表明，在籽粒灌浆期间冠层氮素营养指标(CNNI)自开花期随时间进程的积分累积值与对应时期籽 粒蛋白质积累状况存在显著的定量关系, 其中植株氮积累量(PNA)表现最好。对冠层氮素营养指标的光谱估算, 在不 同品种、氮素水平、生育时期和年度间可以使用统一的光谱模型。根据特征光谱参数-冠层氮素营养指标-籽粒蛋白 质积累量这一技术路径，以冠层氮素营养指标为交接点将两部分模型链接，建立高光谱参数与籽粒蛋白质积累量间 定量方程。经不同年际独立数据的检验, 基于 SDr/SDb-PNA-GPA 技术路径建立模型可以估算小麦籽粒生长过程中 蛋白质积累动态，预测精度和相对误差分别为 0.954 和 $13.1 \%$ 。因此，利用关键特征光谱参数可以实时监测小麦籽粒 生长进程中蛋白质积累状况。

关键词: 小麦; 光谱信息; 籽粒蛋白质; 积累动态; 监测模型

\section{Monitoring Grain Protein Accumulation Dynamics with Canopy Reflectance Spectra in Wheat}

\author{
FENG Wei ${ }^{1,2}$, ZHU Yan $^{1}$, CAO Wei-Xing ${ }^{1, *}$, ZHU Yun-Ji ${ }^{2}$, and GUO Tian-Cai ${ }^{2}$ \\ ${ }^{1}$ Nanjing Agricultural University / Hi-Tech Key Laboratory of Information Agriculture of Jiangsu Province, Nanjing 210095, China; ${ }^{2}$ Henan Agricul- \\ tural University / National Engineering Research Centre for Wheat, Zhengzhou 450002, China
}

\begin{abstract}
Grain protein is an important index indicating wheat quality status, and nondestructive and quick assessments of grain protein accumulation dynamics is necessary for cultural regulation and quality classification in wheat (Triticum aestivum L.) production. The objectives of this study were to determine the relationships between plant nitrogen nutrition status, grain protein accumulation, and canopy reflectance spectra in winter wheat, therefore, to derive regression equations for monitoring grain protein accumulation with canopy hyper-spectral remote sensing. Three types of cultivars, i.e., high protein content (Xuzhou 26 and Yumai 34), medium protein content (Yangmai 10, Yangmai 12, and Huaimai 20), and low protein content (Ningmai 9) were used in three field experiments under different nitrogen levels in the growing seasons of 2003-2006. Time-course measurements were taken on canopy hyperspectral reflectance, plant weight, nitrogen content and grain protein accumulation (GPA) during the experimental periods. The results showed that the cumulative value of canopy nitrogen nutrition index (CNNI) from anthesis to specific day were highly correlated with grain protein accumulation at corresponding day across grain filling with the best predictor of plant $\mathrm{N}$ accumulation (PNA). According to the regression analyses between vegetation indices and canopy nitrogen nutrition index, several key spectral parameters could accurately estimate the changes in plant $\mathrm{N}$ status across different growth stages, nitrogen levels, and growing seasons with the same spectral parameters for each wheat cultivar. According to the technical route of key spectral parameters-canopy $\mathrm{N}$ nutrition index-grain protein accumulation, estimating models on grain protein accumulation were constructed on the basis of canopy hyper-spectral parameters by linking the above two models with canopy N nutrition index as intersection in wheat. Tests with other independent dataset showed that the key spectral index SDr/SDb on the basis of the technical route of $\mathrm{SDr} / \mathrm{SDb}-\mathrm{PNA}-\mathrm{GNA}$ could be used to predict grain protein accumulation from $7 \mathrm{~d}$ after anthesis to maturity,
\end{abstract}

本研究由国家自然科学基金项目(30671215, 30871448)和国家“十一五”科技支撑计划重大项目(2008BADA4B02, 2006BAD02A07)资助。

*通讯作者(Corresponding author): 曹卫星, E-mail: caow@njau.edu.cn

第一作者联系方式：E-mail: fengwei78@126.com

Received(收稿日期): 2008-11-24; Accepted(接受日期): 2009-03-16. 
with the predictive precision $\left(R^{2}\right)$ of 0.954 and the relative error (RE) of $13.1 \%$, respectively. It can be concluded that dynamic change of grain protein accumulation in wheat could be monitored directly with key vegetation spectral index.

Keywords: Wheat (Triticum aestivum L.); Canopy spectral information; Grain protein; Accumulation dynamics; Monitoring model

冠层反射光谱能够反映作物群体面源信息, 通 过对冠层光谱信息的解析, 可以有效提取和突出作 物目标的实时信息 ${ }^{[1-2]}$ 。许多年来农业遥感应用研究 主要集中在叶面积指数、生物量、叶绿素和氮素营 养等方面 ${ }^{[3-6]}$, 进而对作物生长特征和植株氮素状况 进行有效的动态监测。而谷类作物的籽粒品质性状 无损监测研究起步较晚, 目前利用冠层光谱预测成 熟期籽粒蛋白质状况已成为研究热点。Hansen 等 ${ }^{[7]}$ 报道了用冠层光谱反射率和偏最小二乘法预测小麦 籽粒蛋白质含量的方法。薛利红等 ${ }^{[8]}$ 认为, 拔节期、 孕穗期和灌浆期的光谱反射率与水稻成熟期籽粒蛋 白质含量呈极显著相关。Wang 等 ${ }^{[9]}$ 研究表明, 小麦 开花期和灌浆期植株色素比值指数(PPR)能够很好 预测成熟期籽粒蛋白质含量。李映雪等 ${ }^{[10]}$ 指出, 灌 浆中期冠层光谱指数 RVI (1 220,710)能够反映不同 小麦品种成熟期籽粒蛋白质含量的变化。籽粒蛋白 质积累量为籽粒蛋白质含量和籽粒重量的乘积, 是 表征籽粒蛋白质性状的又一个重要指标, 前人对此 进行光谱法快速预测也开展了一些相关研究。 Basnet 等 ${ }^{[11}$ 研究了卫星影像信息与谷类作物籽粒蛋 白质积累的关系。田永超 ${ }^{[12]}$ 等认为抽穗后冠层植被 指数 $\mathrm{R}_{1500} / \mathrm{R}_{610}$ 与小麦籽粒蛋白质积累量呈极显著的 指数关系。然而, 以上研究侧重于对成熟期籽粒蛋 白质状况的评价, 有关籽粒灌浆期间蛋白质形成动 态的光谱反演未见报道, 并且籽粒蛋白质积累动态 的特征光谱参数及与冠层反射光谱的定量关系需要 深入研究探讨。

本研究以不同年份、品种类型和施氮水平的田 间试验为基础, 系统分析了小麦籽粒蛋白质积累动 态的适宜农学指标, 综合建立了小麦多生育期冠层 氮素营养状况与对应高光谱参数的定量关系, 以期 确立小麦籽粒生长过程中蛋白质积累动态的适宜光 谱参数和定量估算模型, 为小麦籽粒品质监测和管 理调控提供理论基础与技术途径。

\section{1 材料与方法}

\section{1 试验设计}

试验 1 (EXP.1)于 2003-2004 年在江苏省农业 科学院试验田进行, 供试小麦品种为宁麦 9 号(蛋白
质含量低, 约 $10 \%$ )、淮麦 20 和扬麦 10 号(蛋白质含 量中, 分别为 $12 \%$ 和 $13 \%$ 左右)、徐州 26 (蛋白质含 量高, 约 $15 \%$ )。前茬水稻, 土壤质地为黄棕壤, 含 有机质 $0.96 \%$ 、全氮 $0.10 \%$ 、速效磷 $40.29 \mathrm{mg} \mathrm{kg}^{-1}$ 、 速效钾 $102.78 \mathrm{mg} \mathrm{kg}^{-1}$ 。设 5 个施氮水平, 分别为 0 、 75、150、225 和 $300 \mathrm{~kg} \mathrm{hm}^{-2}$ 纯氮, $60 \%$ 作基肥, 拔 节肥和孕穗肥各占 $20 \%$; 配施 $\mathrm{P}_{2} \mathrm{O}_{5} 150.0 \mathrm{~kg} \mathrm{hm}^{-2}$ 和 $\mathrm{K}_{2} \mathrm{O} 112.5 \mathrm{~kg} \mathrm{hm}^{-2}$, 全部用作基肥。小区面积 $4 \mathrm{~m} \times$ $4 \mathrm{~m}=16 \mathrm{~m}^{2}$, 基本苗为 $1.8 \times 10^{6} \mathrm{hm}^{-2}$, 行距 $25 \mathrm{~cm}$ 。 两因素随机区组排列, 3 次重复。其他管理措施同高 产大田栽培。田间光谱测试和采样期分别为开花期、 灌浆前期、灌浆中期、灌浆后期和成熟期。该试验 资料用于监测模型的检验。

试验 2 (EXP.2)于 2004-2005 年在江苏省农业 科学院试验田进行, 供试品种为宁麦 9 号、扬麦 12 (蛋白含量中, 约 13\%)和豫麦 34 (蛋白含量高, 约 $15 \%)$ 。前茬水稻, 土壤质地为黄棕壤, 含有机质 $2.09 \%$ 、全氮 $0.18 \%$ 、速效氮 $150.20 \mathrm{mg} \mathrm{kg}^{-1}$ 、速效 磷 $140.03 \mathrm{mg} \mathrm{kg}^{-1}$ 、速效钾 $113.50 \mathrm{mg} \mathrm{kg}^{-1}$ 。设 4 个 施氮水平, 分别为 $0 、 75 、 150$ 和 $225 \mathrm{~kg} \mathrm{hm}^{-2}$ 纯氮, 50\%用作基肥，50\%为拔节期追肥; 基肥配施 $80 \mathrm{~kg}$ $\mathrm{hm}^{-2} \mathrm{P}_{2} \mathrm{O}_{5}$ 和 $150 \mathrm{~kg} \mathrm{hm}^{-2} \mathrm{~K}_{2} \mathrm{O}$ 。另外, 各品种均设置 一个氮磷钾空白处理 $(\mathrm{CK})$ 。试验小区随机排列, 3 次 重复, 小区面积 $4.0 \mathrm{~m} \times 4.5 \mathrm{~m}=18.0 \mathrm{~m}^{2}$, 基本苗 $1.5 \times$ $10^{6} \mathrm{hm}^{-2}$, 行距 $25 \mathrm{~cm}$ 。其他栽培管理措施同一般高 产麦田。田间光谱测试和采样期分别为拔节期、孕 穗期、开花期、灌浆前期、灌浆中期、灌浆后期和 成熟期。该试验资料用于建立监测模型。

试验 3 (EXP.3)于 2005-2006 年在江苏省南京 市农林局科学试验田进行, 供试品种为宁麦 9 号和 豫麦 34。前茬水稻, 土壤质地为黄棕壤, 含有机质 $1.43 \%$ 、全氮 $0.11 \%$ 、速效氮 $62.5 \mathrm{mg} \mathrm{kg}^{-1}$ 、速效磷 $10.4 \mathrm{mg} \mathrm{kg}^{-1}$ 、速效钾 $82.5 \mathrm{mg} \mathrm{kg}^{-1}$ 。设 4 个施氮水 平, 分别为 $0 、 90 、 180$ 和 $270 \mathrm{~kg} \mathrm{hm}^{-2}$ 纯氮, 配施 $150 \mathrm{~kg} \mathrm{hm}^{-2} \mathrm{P}_{2} \mathrm{O}_{5}$ 和 $210 \mathrm{~kg} \mathrm{hm}^{-2} \mathrm{~K}_{2} \mathrm{O}$, 磷钾肥全部用 作基肥，处理的氮肥 50\%用作基肥, 50\%为拔节期追 肥。试验随机排列, 3 次重复, 小区面积 $5.0 \mathrm{~m} \times 5.5 \mathrm{~m}$ $=27.5 \mathrm{~m}^{2}$, 基本苗 $1.8 \times 10^{6} \mathrm{hm}^{-2}$, 行距 $25 \mathrm{~cm}_{\text {。 }}$ 其他 栽培管理措施同一般高产麦田。田间光谱测试和采 
样期分别为拔节期、孕穗期、抽穗期、开花期、灌 浆前期、灌浆中期、灌浆后期和成熟期。该试验资 料用于建立监测模型。

\section{2 光谱数据的测定}

采用美国 Analytical Spectral Device (ASD)公司 生产的 FieldSpec Pro FR2500 型背挂式野外高光谱 辐射仪测量小麦冠层光谱, 波段值为 350 2 $500 \mathrm{~nm}$, 其中, 350 1 $000 \mathrm{~nm}$ 光谱采样间隔为 $1.4 \mathrm{~nm}$, 光谱分 辨率为 $3 \mathrm{~nm} ; 1000 \sim 2500 \mathrm{~nm}$ 光谱采样间隔为 $2 \mathrm{~nm}$, 光谱分辨率为 $10 \mathrm{~nm}$ 。测定选择在天气晴朗、无风 或风速很小时, 时间范围为 10:00 14:00, 传感器探 头垂直向下, 光谱仪视场角为 $25^{\circ}$, 距冠层顶垂直高 度约 $1.0 \mathrm{~m}$, 地面视场范围直径为 $0.44 \mathrm{~m}$ 。以 10 条 光谱为一采样光谱, 每个小区每次记录 10 个采样光 谱, 以其平均值作为该小区的光谱反射值。测量过 程中及时进行标准白板校正 (标准白板反射率为 1 , 这样所得的目标物光谱是无量纲的相对反射率), 对 每组目标的观测前后均以参考板标定。

\section{3 农学参数的测定与计算}

与光谱测量同步, 每小区取小麦 20 株, 孕穗 期以后取小麦 60 个单茎, 将植株分离为叶片和茎 鞘, 并自灌浆开始从穗部剥离籽粒, 在 $105^{\circ} \mathrm{C}$ 下杀 青 $20 \mathrm{~min}$ 并在 $80^{\circ} \mathrm{C}$ 下烘干后称重。利用 CID-301 型叶面积仪测定采样植株绿叶面积, 进而计算单 位土地面积内的绿叶面积 (叶面积指数, LAI)。将 样品粉碎后, 采用凯氏定氮法, 测定叶片、茎鞘、 颖壳和籽粒等部位的全氮含量 $(\%)$ 。叶片氮素积累 量(LNA, $\mathrm{g} \mathrm{N} \mathrm{m}^{-2}$ ) $=$ 叶片氮含量 (LNC, \%) ×叶片干 物重 $\left(\mathrm{g} D \mathrm{DW} \mathrm{m} \mathrm{m}^{-2}\right)$ 。叶面积氮指数 $(\mathrm{LANI})=\mathrm{LNC} \times$ LAI。植株氮积累量(PNA), 在小麦拔节至孕穗期 为叶片与茎鞘氮素积累量的总和, 在抽穗至开花 期为叶片、茎鞘、穗轴和颖壳氮素积累量的总和(此 时没有形成籽粒), 在灌浆至成熟期为剥去籽粒余 下的部分(包括叶片、茎鞘、穗轴和颖壳)的氮素总 和。小麦籽粒蛋白质含量 $(\%)$ 为籽粒全氮含量乘以 系数 5.823 , 籽粒蛋白质积累量 (GPA, $\mathrm{g} \mathrm{N} \mathrm{m}^{-2}$ ) = 籽粒蛋白质含量 $(\%) \times$ 籽粒重量 $\left(\mathrm{g} \mathrm{DW} \mathrm{m}^{-2}\right)$ 。

冠层氮素营养指标 $(\mathrm{CNNI})$ 在开花期至特定日期 的累加值 (cumulative value, 记作 $\sum$ ) 可通过积分获 得, 即为冠层氮素营养指标随开花后天数的动态曲 线与日期进程(天数)所围面积。

$$
C C N N I(A-S)=\sum C N N I s=\int_{A}^{S} C N N I d t=\sum_{A}^{S} C N N I i
$$

式中, $\mathrm{CCNNI}(\mathrm{A} \sim \mathrm{S})$ 为小麦开花期至开花至成 熟中某一特定日期的冠层氮素营养指标的积分累 加值 (记作 $\Sigma C N N I s$ ), $A$ 和 $S$ 分别为开花期和某一特 定日期对应的开花后天数。

\section{4 数据分析与利用}

综合现有的多个光谱分析技术，如光谱位置变 量技术、微分光谱技术、连续统去除法和原始光谱 反射率多波段组合等, 以减小背景噪音的影响, 提 高光谱参数对目标物的敏感性。红边面积 $(\mathrm{SDr})$ 为 680 755 nm 区域内一阶微分光谱总和, 蓝边面积 (SDb)为 490 530 $\mathrm{nm}$ 区域内一阶微分光谱总和, 将 红边面积和蓝边面积进行组合可以构造不同形式的 植被指数。光谱信息提取及参数计算在 MATLAB 语 言环境下编程实现, 并对试验数据进行综合分析。 以试验 2 和试验 3 的资料对不同生育时期及不同表 达形式的冠层氮素营养指标与对应时期的籽粒蛋白 质积累量进行相关回归分析，并建立定量模型。同 时对小麦冠层多个光谱参数与冠层氮素营养指标进 行多时期相关分析, 并通过回归分析建立小麦冠层 氮素营养动态监测模型。根据特征光谱参数-冠层氮 素营养指标-籽粒蛋白质积累量这一技术路径，以 小麦冠层氮素营养指标为交接点, 将基于光谱参数 的冠层氮素营养指标监测模型与基于冠层氮素营养 的籽粒蛋白质积累量定量方程两部分模型进行链接, 建立基于高光谱参数的小麦籽粒蛋白质积累动态定 量估算模型。最后, 以试验 1 中的独立试验资料对 以上监测模型进行分时期测试和检验，并绘制观察 值与预测值之间 1：1 关系图。

\section{2 结果与分析}

\section{1 小麦氮素营养与籽粒蛋白质积累动态的关} 系

综合试验 2 和试验 3 资料, 对叶片氮素含量、 LNA 和 LANI 与灌浆期间籽粒蛋白质积累量进行相 关分析(表 1), 不同时期不同形式叶片氮素营养指标 与籽粒蛋白质积累量间相关性在测定的所有时期均 达显著水平，但通过回归分析，发现不同时期间斜 率和截距存在较大差异, 将灌浆期 3 次试验资料综 合分析, 相关系数则表现不显著。LNA 能很好地指 示氮素营养状况，且开花后植株氮素再转运对籽粒 蛋白质形成具有较大作用，因此植株氮积累量高低 与籽粒蛋白质状况关系密切。与叶片氮素营养指标 相似, 植株氮积累量与籽粒蛋白质积累量间相关性 
在测定的所有时期均达显著水平, 但将 3 次灌浆期 的数据综合分析相关系数表现不显著。这表明直接
利用冠层氮素营养指标很难预测籽粒蛋白质积累动 态。

表1 小麦冠层氮素营养状况与籽粒蛋白质积累量的相关系数

Table 1 Correlation coefficients between canopy $\mathbf{N}$ accumulation status and grain $\mathrm{N}$ accumulation in wheat

\begin{tabular}{|c|c|c|c|c|c|}
\hline $\begin{array}{c}\text { 指标 } \\
\text { Indicator }\end{array}$ & $\begin{array}{c}\text { 灌浆前期 } \\
\text { Initial filling } \\
(n=68)\end{array}$ & $\begin{array}{c}\text { 灌浆中期 } \\
\text { Middle filling } \\
\quad(n=68)\end{array}$ & $\begin{array}{c}\text { 灌浆后期 } \\
\text { Late filling } \\
(n=68)\end{array}$ & $\begin{array}{c}\text { 整个灌浆期 } \\
\text { Whole grain-filling } \\
\text { period }(n=204) \\
\end{array}$ & $\begin{array}{c}\text { 开花至成熟期 } \\
\text { Anthesis to maturity } \\
(n=272)\end{array}$ \\
\hline LNC & $0.638^{* *}$ & $0.742^{* *}$ & $0.488^{* *}$ & $-0.240^{* *}$ & - \\
\hline LNA & $0.860^{* *}$ & $0.842^{* *}$ & $0.801^{* *}$ & -0.039 & - \\
\hline LANI & $0.838^{* *}$ & $0.838^{* *}$ & $0.778^{* *}$ & -0.034 & - \\
\hline PNA & $0.861^{* *}$ & $0.887^{* *}$ & $0.886^{* *}$ & 0.075 & - \\
\hline$\Sigma \mathrm{LNC}$ & $0.623^{* *}$ & $0.844^{* *}$ & $0.837^{* *}$ & $0.885^{* *}$ & $0.914^{* *}$ \\
\hline$\Sigma$ LNA & $0.769^{* *}$ & $0.913^{* *}$ & $0.922^{* *}$ & $0.911^{* *}$ & $0.928^{* *}$ \\
\hline$\Sigma$ LANI & $0.752^{* *}$ & $0.891^{* *}$ & $0.907^{* *}$ & $0.895^{* *}$ & $0.914^{* *}$ \\
\hline$\Sigma$ PNA & $0.775^{* *}$ & $0.909^{* *}$ & $0.927^{* *}$ & $0.919^{* *}$ & $0.930^{* *}$ \\
\hline
\end{tabular}

${ }^{* *}$ 在 0.01 水平上显著; LNC：叶片氮含量; LNA：叶片氮积累量; LANI：叶面积氮指数; PNA：植株氮积累量; $\Sigma$ LNC：叶片氮含量

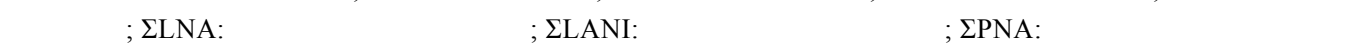

${ }^{* *}$ Significantly different at 0.01 probability level; LNC: leaf N content; LNA: leaf N accumulation; LANI: leaf area N index; PNA: plant $\mathrm{N}$ accumulation; $\Sigma \mathrm{LNC}$ : cumulative value of leaf $\mathrm{N}$ content from anthesis to a given day during grain filling; $\Sigma$ LNA: cumulative value of leaf $\mathrm{N}$ accumulation from anthesis to a given day during grain filling; $\Sigma$ LANI: cumulative value of leaf area $\mathrm{N}$ index from anthesis to a given day during grain filling; $\Sigma$ PNA: cumulative value of plant $\mathrm{N}$ accumulation from anthesis to a given day during grain filling.

综合试验 2 和试验 3 资料, 对冠层氮素营养指 标的积分累加值与对应日期籽粒蛋白质积累量进行 相关分析(表 1)。结果表明, 灌浆期间不同测定日期 冠层氮素营养指标的积分累加值与籽粒蛋白质积累 量间相关系数在测定的所有时期均达显著水平，以 灌浆后期表现最高, 灌浆前期稍差, 通过回归分析, 发现不同时期间斜率和截距存在较小差异, 将灌浆 期的 3 次测试资料综合分析, 相关系数依然极显著,
把灌浆期和成熟期 4 次测试资料综合分析，相关系 数进一步提高, 从而可以建立冠层氮素营养指标的 积分累加值与籽粒蛋白质积累量间的总体定量关 系。进一步回归分析还发现，利用叶片氮含量的积 分累加值作为预测指标，籽粒蛋白质积累量在 20 60 $\mathrm{g} \mathrm{m}^{-2}$ 时明显偏离拟合曲线，而利用其他冠层 氮素指标的积分累加值预测籽粒蛋白质积累动态效 果很好(图 1)。
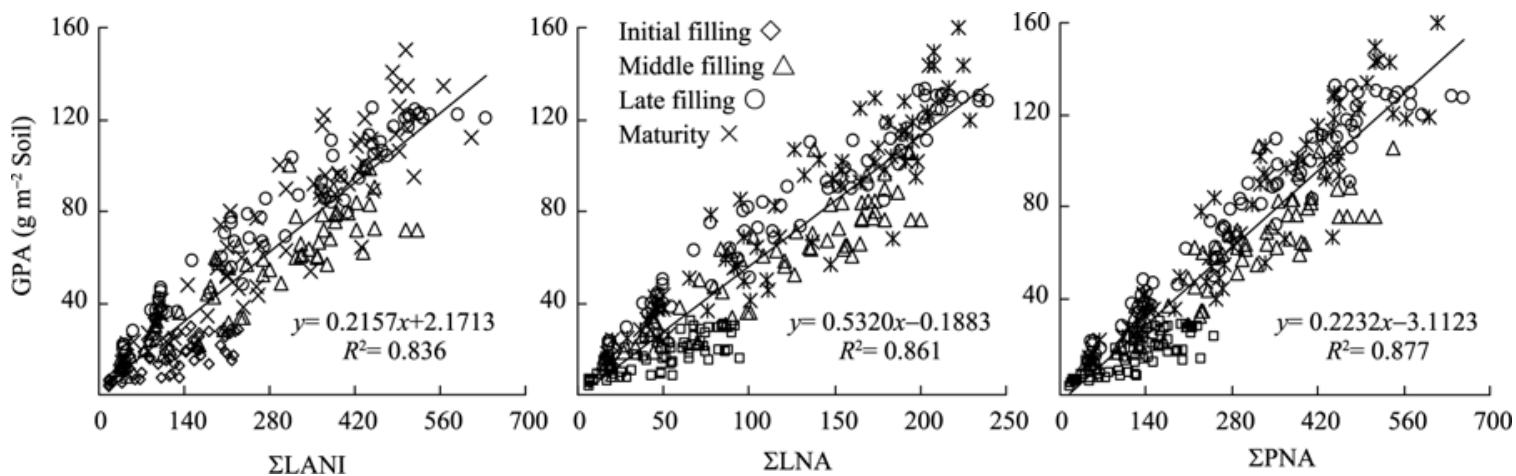

图 1 小麦籽粒生长过程中蛋白质积累量与冠层氮素营养累加值的关系

Fig. 1 Relationship of grain protein accumulation to cumulative value of canopy nitrogen nutrition index during grain growth GPA: 籽粒蛋白质积累量, 其他符号缩写同表 1 。

GPA: Grain protein accumulation, other abbreviations are the same as those given in Table 1.

2.2 小麦冠层氮素营养指标与高光谱参数的关系 以特征光谱及已见报道的多种植被指数为基础, 综合不同年份和生育时期的小麦氮素营养指标与冠 层光谱参数分别进行相关回归分析, 其中 $\mathrm{SDr} / \mathrm{SDb}$
表现较好，对叶面积氮指数、叶片氮积累量及植株 氮积累量方程拟合均表现很好, 决定系数 $\left(R^{2}\right)$ 分别 为 $0.918 、 0.850$ 和 0.824 , 方程估计标准误差 $(S E)$ 分 别为 $2.97 、 1.11$ 和 2.43 , 表明小麦拔节至灌浆后期 
冠层氮素营养状况动态化可以使用统一的光谱指数 $\mathrm{SDr} / \mathrm{SDb}$ 来表达(图 2)。
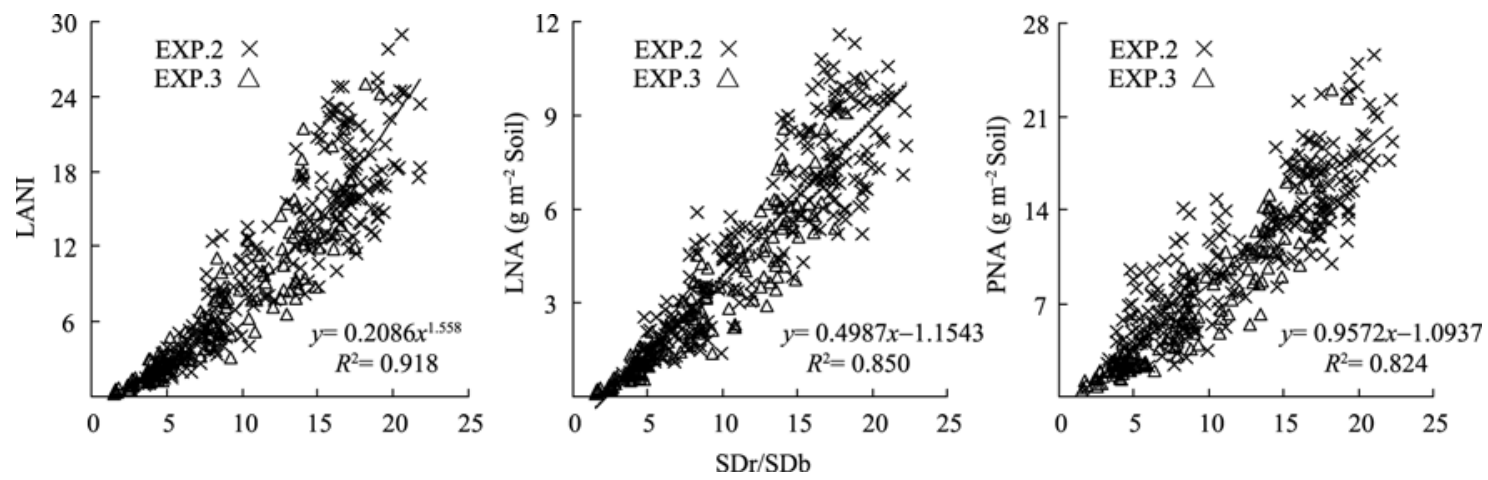

图 2 小麦冠层氮素营养指标与光谱参数 SDr/SDb 的关系

Fig. 2 Relationship of canopy nitrogen nutrition index to SDr/SDb in wheat $\mathrm{SDr} / \mathrm{SDb}$ : 红边微分面积与蓝边微分面积的比值。

$\mathrm{SDr} / \mathrm{SDb}$ : ratio of sum of the 1 st order derivative values within the red edge to that within the blue edge.

2.3 小麦灌浆期籽粒蛋白质积累动态监测模型 的建立及检验

由于冠层氮素营养的累加值与籽粒蛋白质积累 量间存在显著的定量关系, 同时冠层氮素营养的光 谱监测模型估算精度较高, 因此以冠层氮素营养为 交接点, 根据特征光谱参数-冠层氮素营养-籽粒蛋 白质积累量这一技术路径, 将以上两套模型有机链 接, 建立高光谱参数与小麦籽粒蛋白质积累动态间 定量模型，其过程如下。

籽粒蛋白质积累量 (GPA)与冠层氮素营养指标 (CNNI) 间定量关系:

$$
G P A=a \times \sum_{A}^{S} C N N I_{i}+b
$$

冠层氮素营养指标 $(\mathrm{CNNI})$ 与光谱植被指数 $(\mathrm{VI})$ 间定量关系:

$$
C N N I=c \times V I+d \text { 或 } C N N I=c \times V I^{d}
$$

将式(2)代入式(1)中, 建立光谱植被指数与小麦 籽粒蛋白质积累量间定量关系:

$$
\begin{gathered}
G P A=a \times \sum_{A}^{S}\left(c \times V I_{i}+d\right)+b \text { 或 } \\
G P A=a \times \sum_{A}^{S}\left(c \times V I_{i} d\right)+b
\end{gathered}
$$

利用对冠层氮素营养指标反应敏感的光谱参数 $\mathrm{SDr} / \mathrm{SDb}$, 建立植被指数与小麦籽粒蛋白质积累量 间定量关系。为了考察模型的可靠性和普适性, 利 用试验 1 独立试验数据对基于不同路径模型建立的 监测方程分别进行验证, 模型的预测能力如表 2 所 示, 并对表现较好的检验结果作 1：1 关系图直观展
示测试效果(图 3)。表 2 结果表明, SDr/SDb-LANIGPA 路径模型在花后 $7 \mathrm{~d}$ 和 $14 \mathrm{~d}$ 预测误差大于 $20 \%$, 尽管在花后 $21 \mathrm{~d}$ 平均预测效果较好 $(R E<20 \%)$, 但 误差大于 $20 \%$ 的检验样本比例为 $33 \%$, 而花后 $28 \mathrm{~d}$ 及成熟期预测误差较小且大于 $20 \%$ 的检验样本比例 也很少, 表明 SDr/SDb-LANI-GPA 路径模型只能有 效预测灌浆后期的籽粒蛋白质积累量状况。 SDr/SDb-LNA-GPA 模型在花后 $7 \mathrm{~d}$ 和 $14 \mathrm{~d}$ 以及 $21 \mathrm{~d}$ 预测结果较差, 仅在花后 $28 \mathrm{~d}$ 和成熟期误差小于 $20 \%$, 但误差大于 $20 \%$ 的样本比例较高。 $\mathrm{SDr} /$ SDb-PNA-GPA 模型在灌浆进程中的不同测定日期 及成熟期均给出理想的测试结果, 且随籽粒灌浆进 程的推进预测误差减小，成熟期预测误差为 9\%, 籽 粒灌浆的不同阶段预测误差大于 $20 \%$ 的样本比例均 较低, 花后 $7 \mathrm{~d}$ 至成熟期平均预测误差为 $13.1 \%$, 预 测精度达 0.957 , 表明该路径模型能很好预测小麦灌 浆期籽粒蛋白质积累动态(图 3)。

由表 2 还可看出, 生育时期、氮素水平和品种 类型对蛋白质积累动态模型预测和检验具有重要影 响。随籽粒灌浆进程的推进预测误差呈减小趋势, 同时误差大于 $20 \%$ 的样本比例也降低。在低氮水平 下预测误差偏大, 误差大于 $20 \%$ 的样本比例较高, 而在高氮条件下预测误差较好, 误差大于 $20 \%$ 的样 本比例减少。比较而言, 高蛋白类型品种预测误差 较小, 误差大于 $20 \%$ 的样本比例也较低, 而低蛋白 类型品种则相反。这表明蛋白质积累动态模型对高 施氮条件下高蛋白类型品种在灌浆中后期预测效果 较好, 其中以 $\mathrm{SDr} / \mathrm{SDb}-\mathrm{PNA}-\mathrm{GPA}$ 路径模型表现最 突出。 
表2＼cjkstart基于不同模型的小麦籽粒蛋白质积累量预测值与实测值间相对误差

Table 2 Relative error between predicted and observed grain protein accumulation based on different models in wheat

\begin{tabular}{|c|c|c|c|c|c|c|c|c|c|}
\hline \multirow[b]{2}{*}{$\begin{array}{c}\text { 指标 } \\
\text { Indicator }\end{array}$} & \multicolumn{3}{|c|}{ SDr/SDb-LANI-GPA } & \multicolumn{3}{|c|}{$\mathrm{SDr} / \mathrm{SDb}-\mathrm{LNA}-\mathrm{GPA}$} & \multicolumn{3}{|c|}{$\mathrm{SDr} / \mathrm{SDb}-\mathrm{PNA}-\mathrm{GPA}$} \\
\hline & $\begin{array}{c}\text { 相对误差 } \\
\text { Relative } \\
\text { error (RE) }\end{array}$ & $\begin{array}{c}\text { 变幅 } \\
\text { Range of } \\
\text { RE }\end{array}$ & $\begin{array}{c}\text { 误差大于 } \\
0.2 \text { 的比例 } \\
\text { Ratio of } \\
\text { RE }>0.2\end{array}$ & $\begin{array}{c}\text { 相对误差 } \\
\text { Relative } \\
\text { error (RE) }\end{array}$ & $\begin{array}{c}\text { 变幅 } \\
\text { Range of } \\
\text { RE }\end{array}$ & $\begin{array}{c}\text { 误差大于 } \\
0.2 \text { 的比例 } \\
\text { Ratio of } \\
\text { RE }>0.2\end{array}$ & $\begin{array}{c}\text { 相对误差 } \\
\text { Relative } \\
\text { error (RE) }\end{array}$ & $\begin{array}{c}\text { 变幅 } \\
\text { Range of } \\
\text { RE }\end{array}$ & $\begin{array}{c}\text { 误差大于 } \\
0.2 \text { 的比例 } \\
\text { Ratio of } \\
\text { RE }>0.2\end{array}$ \\
\hline \multicolumn{10}{|c|}{ 生育时期 Growth period } \\
\hline 7DAA & 0.297 & $0.02-0.47$ & 0.57 & 0.262 & $0.01-0.54$ & 0.43 & 0.169 & $0.01-0.30$ & 0.27 \\
\hline 14DAA & 0.243 & $0.01-0.45$ & 0.57 & 0.296 & $0.01-0.63$ & 0.60 & 0.144 & $0.01-0.26$ & 0.23 \\
\hline 21DAA & 0.183 & $0.01-0.34$ & 0.33 & 0.249 & $0.01-0.49$ & 0.53 & 0.131 & $0.01-0.26$ & 0.17 \\
\hline 28DAA & 0.129 & $0.01-0.32$ & 0.13 & 0.188 & $0.01-0.35$ & 0.33 & 0.122 & $0.01-0.24$ & 0.13 \\
\hline Maturity & 0.112 & $0.01-0.23$ & 0.13 & 0.166 & $0.01-0.28$ & 0.37 & 0.09 & $0.01-0.25$ & 0.10 \\
\hline 7DAA to maturity & 0.193 & $0.01-0.47$ & 0.34 & 0.232 & $0.01-0.63$ & 0.45 & 0.131 & $0.01-0.30$ & 0.18 \\
\hline \multicolumn{10}{|l|}{ 氮素水平 $\quad \mathrm{N}$ level } \\
\hline N1 & 0.233 & $0.14-0.30$ & 0.67 & 0.223 & $0.14-0.31$ & 0.50 & 0.186 & $0.13-0.23$ & 0.33 \\
\hline $\mathrm{N} 2$ & 0.208 & $0.15-0.30$ & 0.50 & 0.285 & $0.12-0.38$ & 0.67 & 0.153 & $0.07-0.22$ & 0.17 \\
\hline $\mathrm{N} 3$ & 0.159 & $0.13-0.23$ & 0.33 & 0.256 & $0.16-0.32$ & 0.67 & 0.126 & $0.06-0.19$ & 0.00 \\
\hline N4 & 0.192 & $0.10-0.24$ & 0.33 & 0.229 & $0.12-0.26$ & 0.50 & 0.092 & $0.07-0.14$ & 0.00 \\
\hline N5 & 0.172 & $0.08-0.22$ & 0.33 & 0.168 & $0.10-0.24$ & 0.17 & 0.100 & $0.06-0.17$ & 0.00 \\
\hline \multicolumn{10}{|c|}{ 品种类型 Type of cultivar } \\
\hline LPC & 0.196 & $0.13-0.26$ & 0.50 & 0.240 & $0.17-0.26$ & 0.67 & 0.156 & $0.10-0.21$ & 0.17 \\
\hline MPC & 0.200 & $0.14-0.25$ & 0.33 & 0.257 & $0.19-0.32$ & 0.67 & 0.122 & $0.08-0.17$ & 0.00 \\
\hline HPC & 0.166 & $0.12-0.23$ & 0.17 & 0.212 & $0.15-0.28$ & 0.50 & 0.113 & $0.06-0.16$ & 0.00 \\
\hline
\end{tabular}

DAA：开花后天数; LPC: 蛋白质含量低; MPC:蛋白质含量中; HPC:蛋白质含量高; N1、N2、N3、N4 和 N5 分别表示试验 1 中施 纯氮 $0 、 75 、 150 、 225$ 和 $300 \mathrm{~kg} \mathrm{hm}^{-2}$ 。

DAA: days after anthesis; LPC: low protein content; MPC: medium protein content; HPC: high protein content; N1 to N5 denote nitrogen application rate of $0,75,150,225$, and $300 \mathrm{~kg} \mathrm{hm}^{-2}$ in Experiment 1, respectively.

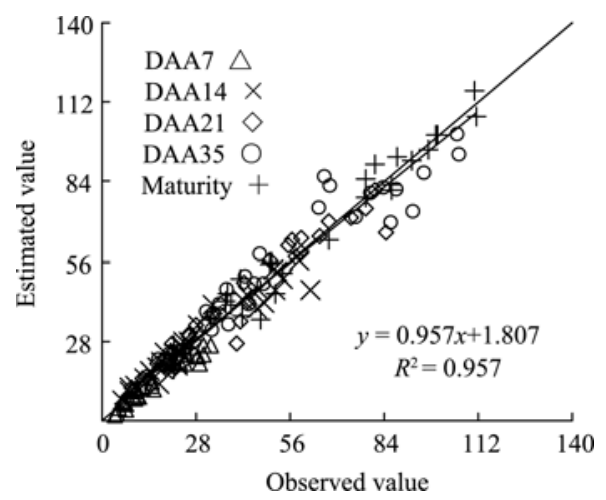

图 3 基于 SDr/SDb-PNA-GPA 模型的小麦䊏粒蛋白质积累量 预测值与实测值间比较

Fig. 3 Comparison of estimated with measured grain protein accumulation based on SDr/SDb-PNA-GPA model in wheat

\section{3 讨论}

小麦籽粒中 $60 \%$ $90 \%$ 氮素来自开花前植株积 累氮的再动员。因此, 成熟期蛋白质含量与生长期 植株氮素营养密切相关 ${ }^{[13-15]}$, 从而可以建立具有农 学机制的定量化算法 ${ }^{[9,16]}$ 。尽管利用单一生育时期农 学参数对小麦成熟期籽粒蛋白质性状能够进行可靠
的预测，但这种模型的预报指标、时期及方程在不 同栽培条件下存在一定差异 ${ }^{[9-10,16]}$ 。小麦在灌浆进程 中植株氮素逐渐向籽粒转移, 籽粒蛋白质积累量不 断增加, 因此难以提取统一的表征籽粒整个灌浆进 程中蛋白质积累动态的农学指标及定量算法。作物 籽粒蛋白质积累是一个动态过程, 即受开花期生长 状况的影响，也受灌浆期植株氮素同化的影响，后 期如遇不良外界因素影响，作物的光合物质生产及 氮素的运输和陉藏均会受到影响, 导致籽粒蛋白质 积累能力下降, 因此, 对于一个较好的定量动态估 算模型, 要能反映籽粒在整个生长过程中蛋白质生 产动态。本研究显示, 单一生育时期叶片氮含量、 叶片氮积累量及叶面积氮指数等氮素营养指标均不 能表达籽粒蛋白质积累动态。通过计算植株氮素指 标自开花期的积分累加值则可以反映籽粒蛋白质积 累的动态趋势，进而确立预报籽粒蛋白质积累动态 的农学参数及定量算法。不过, 虽然该模型具有很 强的农学机理性, 但尚需进行室内化验分析, 因此 并不能真正实现无损快速预报。 
前人利用单一生育期(阶段)光谱参数有效地预 测了成熟期籽粒蛋白质状况 ${ }^{[7-10]}$, 但单一生育期光 谱信息包含的作物信息少, 不能反映籽粒生长变 化。从籽粒充实和蛋白质积累的生理角度分析, 灌 浆期间任一时段植株生长好坏均显著影响籽粒蛋白 质积累, 因此理想的预测模型应包括籽粒灌浆期任 何时段作物长势信息, 反映籽粒生长和蛋白质形成 的变化趋势。红边面积涵盖了红边所有波段信息, 而蓝边面积包括了该区域所有波段信息, 其与群体 长势关系较单波段表现更稳定。同时, 近红外平台 和绿波段对植株长势和氮素营养反应敏感, 通过两 波段组合比值植被指数能够显著提高方程拟合效 果。本文提取了对冠层氮素营养反应敏感的高光谱 参数 $\mathrm{SDr} / \mathrm{SDb}$, 建立了能够很好地监测拔节至灌浆 后期的小麦氮素营养动态的光谱模型。为了解决基 于植株氮素营养的籽粒蛋白质积累动态预报模型等 方法的缺点, 构建真正能够无损快速准确测算籽粒 灌浆过程任一时期蛋白质积累的预报模型, 本文以 冠层氮素营养指标为交接点将基于冠层氮素营养指 标的籽粒蛋白质积累量预测模型和基于高光谱遥感 的冠层氮素营养指标监测模型进行链接, 建立了基 于高光谱特征参数的小麦籽粒蛋白质积累动态预报 模型。但该模型对灌浆时段、氮素水平和品种类型 的反应均存在差异, 高氮条件下高蛋白类型品种在 灌浆中后期预测结果较好, 而在低氮水平、低蛋白 类型品种和灌浆中前期检验误差较大。这是因为高 蛋白品种在高氮条件下氮素代谢旺盛, 籽粒蛋白质 合成迅速, 随着灌浆进程推进, 尤其在灌浆中后期 植株氮代谢水平与蛋白质合成间关系更加密切。表 现较好的 SDr/SDb-PNA-GPA 路径模型在花后 $7 \mathrm{~d}$ 至成熟期平均预测误差在 13\%左右，误差大于 $20 \%$ 的样本比例只有 $18 \%$, 由此建立的光谱监测模型能 够适用于不同年份、品种和氮素水平下小麦籽粒形 成过程中任何时段的籽粒蛋白质积累量, 从而实现 小麦籽粒蛋白质形成进程的动态监测。这为小麦生 产管理和品质分级提供可靠的关键技术, 对于指导 生育后期区域施肥，以稳定提高小麦品质也具有指 导意义。当然, 本文中小麦籽粒蛋白质积累动态的 高光谱监测模型是在一个生态区 3 年大田试验资料 上构建和测试的。若今后能通过不同生态点、不同 生产系统、不同品种类型的广泛检验并不断完善, 实现模型的估测精度和普适性的有效统一, 将在小 麦品质形成的精确监测和高效管理调控中具有更大
的应用价值。

\section{4 结论}

基于冠层氮素营养指标的积分累加值与对应籽 粒蛋白质积累状况的定量关系，通过模型链接技术 构建了小麦籽粒生长进程的蛋白质积累动态光谱监 测模型，从而实现了基于高光谱指数 $\mathrm{SDr} / \mathrm{SDb}$ 的小 麦籽粒品质形成动态的快速无损监测。这将有助于 指导小麦品质分级、区划、种植业结构调整以及调 优栽培生产管理，为遥感技术在精确农业中的直接 应用奠定技术基础。

\section{References}

[1] Huang Z, Turner B J, Dury S J, Wallis I R, Foley W J. Estimating foliage nitrogen concentration from HYMAP data using continuum removal analysis. Remote Sens Environ, 2004, 93: 18-29

[2] Thenkabail P S, Smith R B, Pauw E D. Hyperspectral vegetation indices and their relationships with agricultural crop characteristics. Remote Sens Environ, 2000, 71: 158-182

[3] Liu Z-Y(刘占宇), Huang J-F(黄敬峰), Wu X-H(吴新宏), Dong Y-P(董永平), Wang F-M(王福民), Liu P-T(刘朋涛). Hyperspectral remote sensing estimation models on vegetation coverage of natural grassland. Chin J Appl Ecol (应用生态学报), 2006, 17(6): 997-102 (in Chinese with English abstract)

[4] Ding S-Y(丁圣彦), Li H-M(李昊民), Qian L-X(钱乐祥). Research advances in remote sensing techniques in estimation of vegetation biochemical material content. Chin J Ecol (生态学杂 志), 2004, 23(4): 109-117 (in Chinese with English abstract)

[5] Cho M A, Skidmore A K. A new technique for extracting the red edge position from hyperspectral data: The linear extrapolation method. Remote Sens Environ, 2006, 101: 181-193

[6] Sims D A, Gamon J A. Relationships between leaf pigment content and spectral reflectance across a wide range of species, leaf structures and developmental stages. Remote Sens Environ, 2002, 81: 337-354

[7] Hansen P M, Jørgensen J R, Thomsen A. Predicting grain yield and protein content in winter wheat and spring barley using repeated canopy reflectance measurements and partial least squares regression. J Agric Sci, 2002, 139: 307-318

[8] Xue L-H(薛利红), Zhu Y(朱艳), Zhang X(张宪), Cao W-X(曹卫 星). Predicting wheat grain quality with canopy reflectance spectra. Acta Agron Sin (作物学报), 2004, 30(10): 1036-1041 (in Chinese with English abstract)

[9] Wang Z J, Wang J H, Liu L Y, Huang W J, Zhao C J, Wang C Z. Prediction of grain protein content in winter wheat (Triticum aestivum L.) using plant pigment ratio (PPR). Field Crops Res, 2004, 90: $311-321$

[10］Ｌi Y-X(李映雪), Zhu Y(朱艳), Tian Y-C(田永超), You X-T(尤小 涛), Zhou D-Q(周冬琴), Cao W-X(曹卫星). Relationship of 
grain protein content and relevant quality traits to canopy reflectance spectra in wheat. Sci Agric Sin (中国农业科学), 2005, 38(7): 1332-1338(in Chinese with English abstract)

[11] Basnet B, Apan A, Kelly R, Jensen T, Strong W, Butler D. Relating satellite imagery with grain protein content. In: Proceedings of the Spatial Sciences Conference, Canberra, Australia, 2003. pp 22-27

[12] Tian Y-C(田永超), Zhu Y(朱艳), Cao W-X(曹卫星), Fan X-M(范雪梅), Liu X-J(刘小军). Monitoring protein and starch accumulation in wheat grains with leaf SPAD and canopy spectral reflectance. Sci Agric Sin (中国农业科学), 2004, 37(6): 808-813 (in Chinese with English abstract)

[13] Woodard H J, Bly A. Relationship of nitrogen management to winter wheat yield and grain protein in South Dakota. J Plant Nutr, 1998, 21: 217-233
[14] Gebbing T, Schnyder H. Pre-anthesis reserve utilization for protein and carbohydrate synthesis in grains of wheat. Plant Physiol, 1999, 121: 871-878

[15] Xie Z-J(谢祝捷), Jiang D(姜东), Cao W-X(曹卫星), Dai T-B(戴 廷波), Jing Q(荊奇). Effects of post-anthesis soil water status on the activities of key regulatory enzymes of starch and protein accumulation in wheat grains. J Plant Physiol Mol Biol (植物生理 与分子生物学学报), 2003, 29(4): 309-316(in Chinese with English abstract)

[16] Wang J-H(王纪华), Huang W-J(黄文江), Zhao C-J(赵春江), Yang M-H(杨敏华), Wang Z-J(王之杰). The inversion of leaf biochemical components and grain quality indicators of winter wheat with spectral reflectance. J Remote Sens (遥感学报), 2003, 7: 277-284(in Chinese with English abstract) 